\title{
Dental manifestations of patient with Vitamin D-resistant rickets
}

\begin{abstract}
Andréia Pereira SOUZA ${ }^{1}$, Tatiana Yuriko KOBAYASHI ${ }^{1}$, Natalino LOURENÇO NETO ${ }^{1}$, Salete Moura Bonifácio SILVA ${ }^{1,}$ Maria Aparecida Andrade Moreira MACHADO' ${ }^{1}$, Thais Marchini OLIVEIRA ${ }^{1}$
\end{abstract}

1- Bauru School of Dentistry, University of São Paulo, Bauru, SP, Brazil.

Corresponding address: Thais Marchini Oliveira - Faculdade de Odontologia de Bauru - Universidade de São Paulo - Alameda Dr. Octávio Pinheiro Brisolla, 9-75 - Bauru - SP - 17012-901 - Brazil - Phone: 551432358218 - e-mail: marchini@usp.br

Submitted: March 16, 2013 - Modification: August 23, 2013 - Accepted: September 5, 2013

\section{ABSTRACT}

\begin{abstract}
Datients with Vitamin D-resistant rickets have abnormal tooth morphology such as thin globular dentin and enlarged pulp horns that extend into the dentino-enamel junction. Invasion of the pulp by microorganisms and toxins is inevitable. The increased fibrotic content of the pulp, together with a reduced number of odontoblasts, decreases the response to pulp infection. The most important oral findings are characterized by spontaneous gingival and dental abscesses occuring without history of trauma or caries. Radiographic examinations revealed large pulp chambers, short roots, poorly defined lamina dura and hypoplastic alveolar ridge. These dental abscesses are common and therefore the extraction and pulpectomy are the treatment of choice. The purpose of this article is to report a case of Vitamin D-resistant rickets in a 5 year-old boy, describing the dental findings and the treatment to be performed in these cases.
\end{abstract}

Key words: Rickets. Vitamin D. Hypophosphatemia. Dental pulp.

\section{INTRODUCTION}

Vitamin D-resistant rickets (VDRR), also known as hereditary or familial hypophosphatemia, is characterized by a metabolic disturbance which causes defective calcification of mineralized structures ${ }^{14}$. VDRR is well established genetically as an X-linked dominant metabolic disorder, that may be characterized by persistent hypophosphatemia and hyperphosphaturea associated with decreased renal tubular reabsorption of inorganic phosphates ${ }^{6,8}$.

The prevalence rate is usually reported to be around $1: 20,000^{4,12}$. In this condition, there is deficient mineralization of bone caused by a genetic defect in renal transepithelial transport of phosphate, which leads to a decrease in tubular reabsorption of phosphate and persistent hypophosphatemia. The features of rickets are the main systemic signs, but many children are not diagnosed until about 2-3 years of age. The metabolic disorder is treated with large doses of oral replacement of phosphate ${ }^{4,12}$.

These anomalies lead to discordance between the production and the rate of mineralization of bone matrix, hence the accumulation of unmineralized matrix and poorly mineralized bone, causing as main clinical features severe body deformities, especially bowing of the legs, impaired growth and short stature. Radiologic findings usually include fractures, generalized osteopenia, growth failure, in some cases craniosynostosis may be present and arched or curve legs ${ }^{6,16}$.

Dental findings that are often characteristic include dentin defects, unusually large pulp chambers and enlarged pulp horns, in some cases the enamel is hypoplastic ${ }^{11,14,16}$. These dental problems are more commonly associated with the primary than the permanent dentition ${ }^{6}$. The most common intraoral radiologic findings include large pulp chambers, short roots, poorly defined lamina dura and hypoplastic alveolar ridge ${ }^{16}$.

On histologic analysis, the dentin exhibits large tubular clefts or lacunae and the enlarged pulp horns may extend beyond the dentino-enamel junction ${ }^{5,6}$. The poorly formed dentin and close proximity of the pulp to the tooth surface may lead to a rapid necrosis of the pulp with periapical complications, because the bacterial ingress to the pulp is being facilitated, occurring spontaneous 


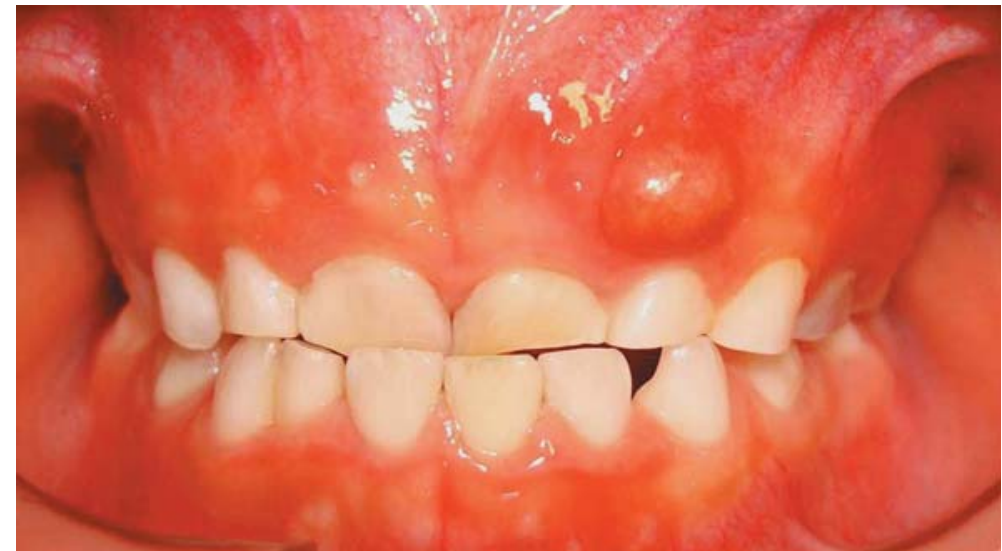

Figure 1- Clinical examinations revealed fistula at the periapical region of primary maxillary left lateral incisor

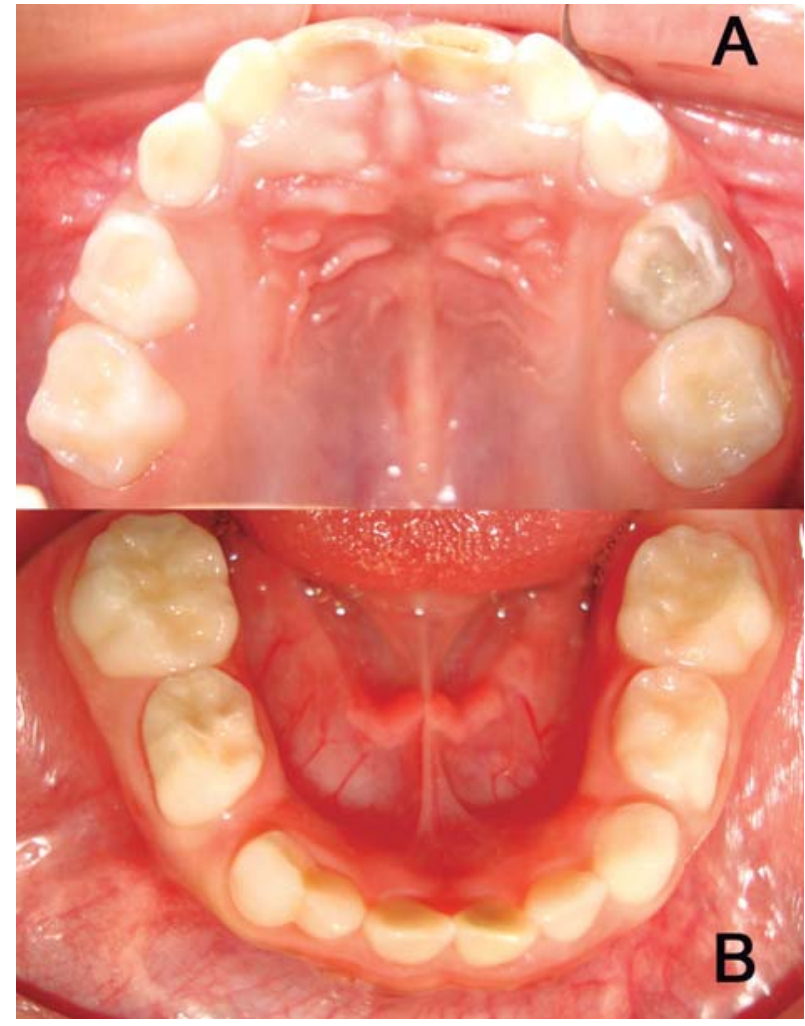

Figure 2A-B- The patient presented complete primary dentition and none of the teeth examined showed evidence of caries

dental abscess without history of trauma or caries $^{6,14}$.

The purpose of this article is to report a case of VDRR in a 5 year-old boy, describing dental findings and treatment.

\section{CASE REPORT}

A 5 year-old boy was referred to the Pediatric Dentistry Clinic with the complaint of "a small ball that appeared in the mouth". During the anamnesis, the patient was diagnosed as having hypophosphatemic vitamin D-resistant rickets. The child was the third twin; however, the parents as well as the siblings, did not have the metabolic disorder. The medicines taken by the patient were calcitriol and phosphate supplements. He presented short stature and several skeletal abnormalities.

Clinical examinations revealed fistula at the periapical region of primary maxillary left lateral incisor without caries or trauma (Figure 1). The patient presented complete primary dentition and none of the teeth examined showed evidence of caries (Figure 2A-B). Radiographic examinations included periapical, panoramic and occlusal views showing pulp chambers enlarged, with pulp horns extending to the dentino-enamel junction, poorly defined lamina dura and hypoplastic alveolar ridge (Figure $2 \mathrm{C}$ ). The patient presented a large physiologic wear of the incisors, geographic tongue and primary mandibular right lateral incisor (\#82) and canine (\#83) with crown alteration (Figure $3 A-B)$. There were areas of rarefaction around the apices of the primary maxillary right and left central incisor (\#51,61), primary maxillary right and left lateral incisor $(\# 52,62)$, primary maxillary right and left canine $(\# 53,63)$ and primary maxillary right and left first molar (\#54,64), primary mandibular right and left central incisor $(\# 81,71)$ (Figure 4 and 5A-B).

Initially, two sections of management were performed. The treatment was divided into two phases: at first, the extraction of the teeth was performed: \#51, 61, 81 and 71. At the second phase, endodontic treatment of the teeth: \#52, 62,53 and 63. These procedures were executed with local anesthesia and rubber dam isolation. The root canals were submitted to preparation with Kerr files and dressing with paramonoclorofenol (Biodinâmica LTDA, Brazil) for 48 hours. Canals were filled with zinc oxid-eugenol and iodoform paste and restored with resin glass ionomer cement (Vitremer, 3M/ESPE, USA).

During the aforementioned treatment, primary mandibular right first molar (\#84), primary 


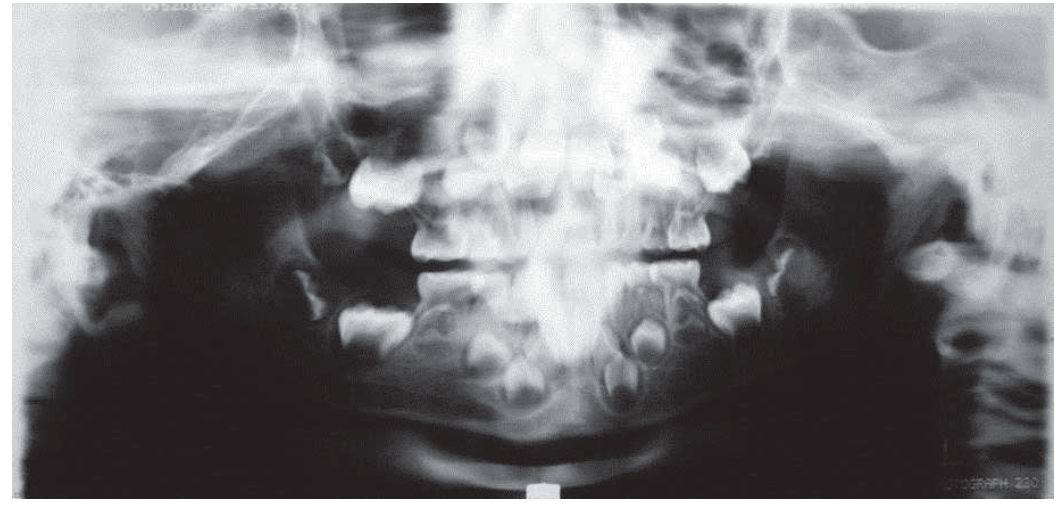

Figure 2C-Panoramic radiography showed the initial conditions
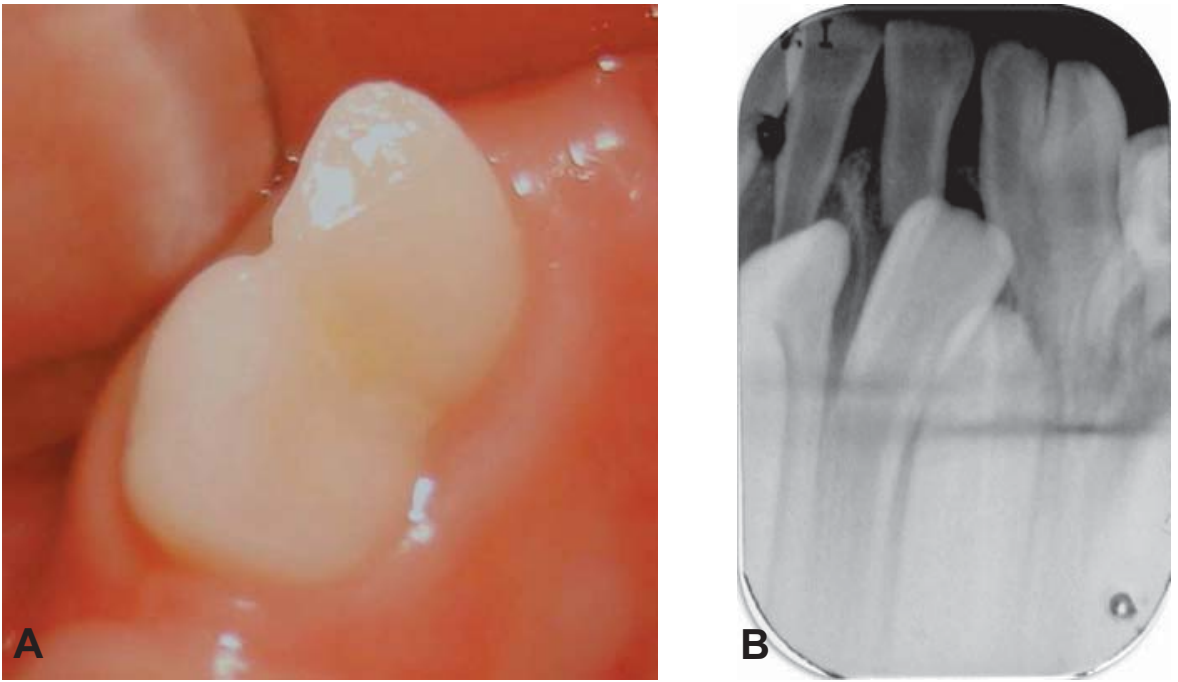

Figure 3A-B- Teeth \#82 and \#83 fused, clinical and periapical radiography

maxillary right and left first molar $(\# 54,64)$ and primary mandibular left second molar (\#75) showed periapical fistula without evidence of caries or trauma in a short-term. These teeth were extracted. However, the child was constantly sick and did not attend the consultations. In the other teeth, the primary mandibular right second molar (\#85), lateral incisor and canine (\#82,83), primary maxillary right and left second molars (\#55,65), primary mandibular left first molar and lateral incisor and canine $(\# 74,73,72)$, the choice of treatment was to open the pulp chambers and make a dressing with formocresol (Biodinâmica LTDA, Brazil). After a 7-day period, the dressing with formocresol was removed and the root instrumentation was performed and filled with zinc oxid-eugenol and iodoform paste, afterwards the teeth were restored with resin glass ionomer cement (Vitremer, 3M/ESPE, USA) (Figure 6).

In order to maintain the space of primary maxillary right and left second molars and primary mandibular right second molar, a fixed spacemaintainer was made and cemented with resin modified glass ionomer cement (Rely X, 3M/ESPE, USA) (Figure 7A-B). The postoperative clinic course

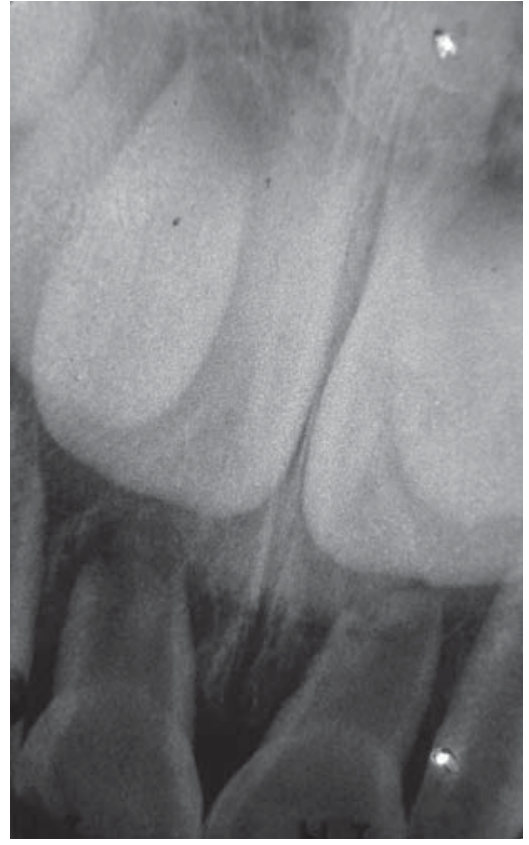

Figure 4- Periapical radiography showed areas of rarefaction around the apices of the primary maxillary right and left central incisor 

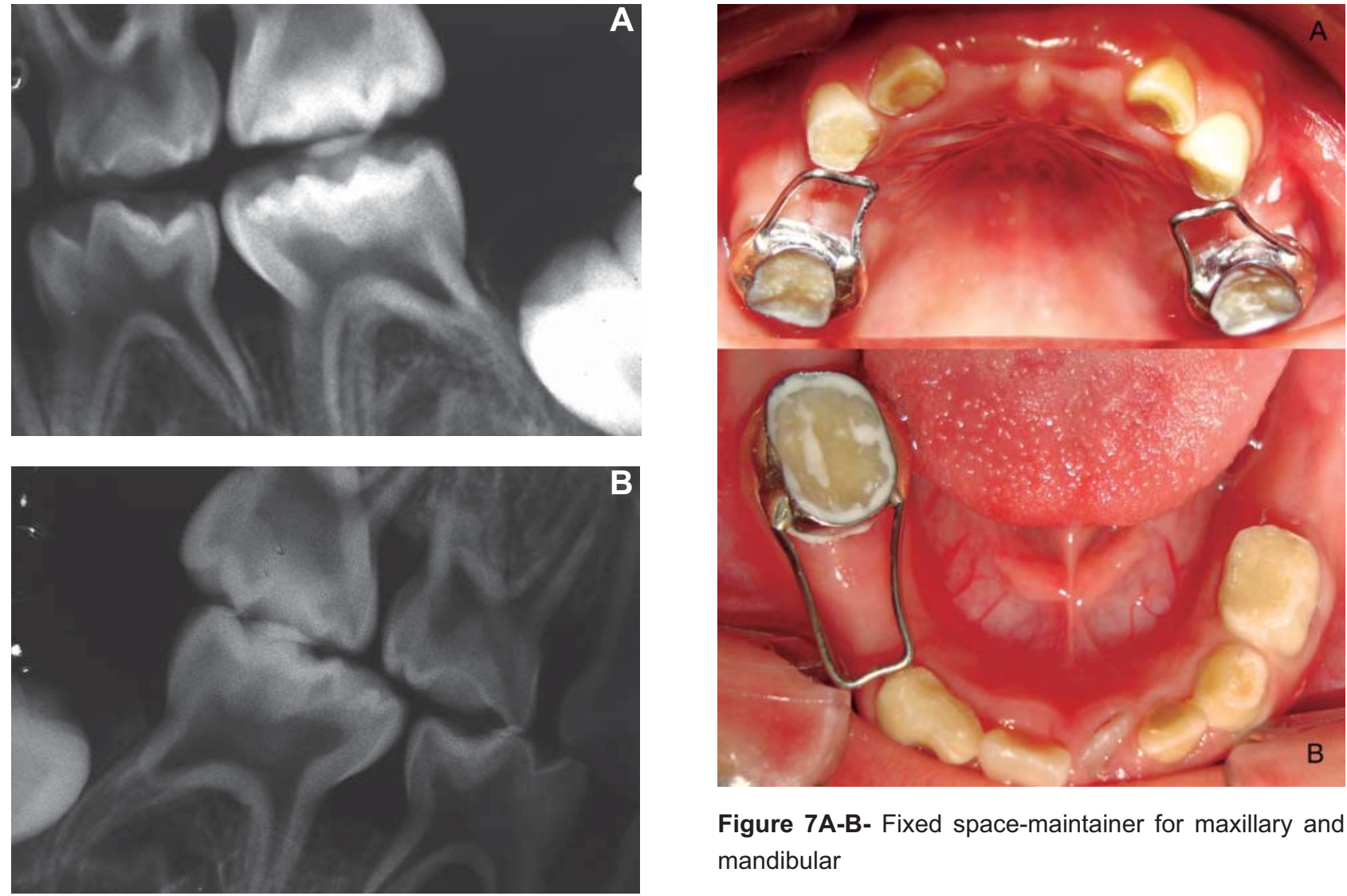

Figure 7A-B- Fixed space-maintainer for maxillary and mandibular

Figure 5A-B- Periapical radiography showed pulp chambers enlarged with pulp horns extending to the dentino-enamel junction

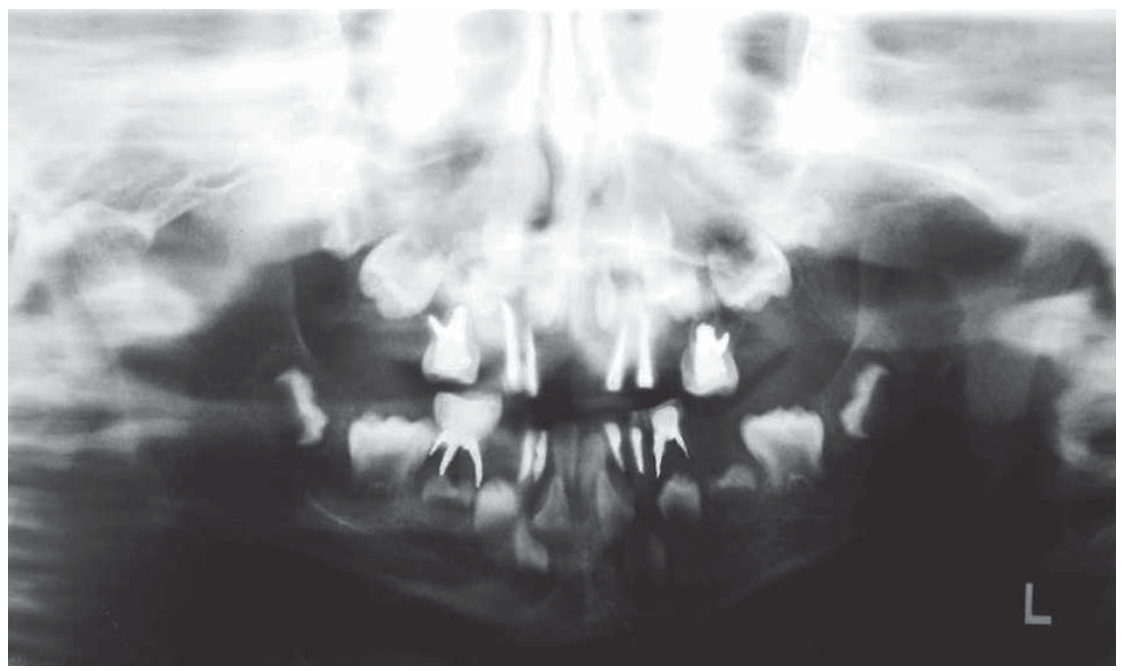

Figure 6- Panoramic radiography showed the final treatment

was uneventful and after six months of follow-up, the child did not show clinical abscesses.

\section{DISCUSSION}

Dental abscesses are frequently observed in VDRR, to the extent that some patients are first diagnosed from the appearance of the spontaneous dental abscesses which are found in the absence of caries or trauma9,12,13. Recurrent abscess formation affecting multiple non-carious primary teeth has been the main clinical feature in the present case. These abscesses are due to deficiencies of dentine mineralization which result in large pulp chambers and physical defects within dentine. In many teeth, there are channels connecting the pulp horns to 
the dentino-enamel junction, and, therefore, when the enamel is lost through attrition or caries, oral microorganisms enter the pulp through these channels ${ }^{9,12,13}$. In the present report, the symptoms were enlarged pulp chambers, poorly calcified dentin and multiple dental abscesses. Of the manifestations, spontaneous dental abscesses are most characteristic of this metabolic disorder and present difficult problems to dentists. These abscesses may be the first sign of a metabolic disorder, such as VDRR, which causes the patient to seek dental attention and then, subsequently, medical evaluation ${ }^{15}$. Andersen, et al. ${ }^{1}$ (2012) showed an increasing frequency of endodontic complications in these patients and the number of affected teeth increase significantly with age. These authors concluded that the need for endodontic treatment among these patients is comprehensive ${ }^{1}$.

The basic dental defects in vitamin D-resistant rickets seem to be manifested in dentin. Enamel is usually reported to be normal. Spontaneous gingival and dental abscesses occur without history of trauma or caries, and radiographic evidence of enlarged pulp chambers with pulpal horns extending beyond the dentino-enamel junction are most important oral findings ${ }^{10}$. Beltes and Zachou ${ }^{2}$ (2012) affirmed that conservative endodontic treatment must be performed in all teeth with pulp necrosis and rarefactions ${ }^{2}$. Both findings and treatment are recognized in the case presented.

According to some authors, the histologic examination showed the penetration of microorganisms through the calcified structures of the enamel layer without visible caries. The microorganisms passed through the dentinoenamel junction and invaded dentin, which was characterized by calcospherites and large amounts of interglobular dentin. Furthermore, microorganisms could be detected in dentinal tubules, which were exposed to the oral cavity when enamel was removed. However, large areas of tertiary dentin extended between such tubules and the pulp. These light microscopic results suggest that clinical manifestations, such as pulp recrosis and periapical lesions, may be caused by the penetration of microorganisms through microclefts of the enamel layer as well as pathologically altered enamel microstructures of affected teeth ${ }^{3,7-9,12}$. These results might explain the clinical problems related to permanent and primary dentition. Further histologic examinations of teeth of the patient are necessary. Patients should be informed of possible dental problems and should seek immediate care when necessary ${ }^{8}$.

As demonstrated in the present case, patients with VDRR have abnormal tooth morphology as thin globular dentin and enlarged pulp horns that extend into the dentino-enamel junction. Invasion of the pulp by microorganisms and toxins is inevitable. The increased fibrotic content of the pulp, together with a reduced number of odontoblasts, decreases the response to pulp infection. In this case, the spontaneous abscesses were common, thus, the extraction and pulpectomy was the treatment of choice. Regardless, the prognosis for spontaneously abscessed teeth in patients with VDRR has been extremely poor ${ }^{3}$.

The main management strategy for the dental manifestations is the prevention of dental abscesses by prophylactic treatment. In the patients, this may be achieved through prophylactic pulp therapy, pulpotomy and pulpectomy, coverage of the molar teeth with stainless steel and restoration of the teeth with composite resins and resin glass ionomer cement $\mathrm{t}^{3,9,12,14}$.

The methodical failure of these treated teeth suggests unhealthy pulps. The general assumption in VDRR patients that microorganisms gain access to the pulp following physiologic attrition may not be entirely accurate. These teeth may erupt with pulpal extensions that communicate with the oral cavity, resulting in microscopic exposures from the time of eruption. The prophylactic pulpotomies are being performed on pulp tissue that is not as healthy as previously believed. Perphaps, the pulps were already infected and the existing condition continued to progress undetected. Since the pulpal health of teeth in these patients may be suspect, a more radical treatment approach of prophylactic pulpectomy may be more beneficial. At this time, there is insufficient evidence to suggest that the recommendation for prophylactic pulpotomy therapy is beneficial in preserving primary dentition in this patient population ${ }^{12}$. Hypothesis had shown no or little effect on dental anomalies as result of treatment with vitamin $D$ and phosphate supplements, therefore, this hypothesis must be explored precisely ${ }^{6}$.

Moreover, to prevent spontaneous dental abscesses as observed in our patient, early conservative endodontic treatment is necessary. In patients with VDRR, professional dental care consisting of periodical examinations, topical fluoride application and the maintenance of good oral hygiene should be performed ${ }^{9}$. Thus, dentists are advised to provide information about the dental characteristics that might first diagnose such patients and that might request referrals to dentist as early as possible to prevent dental infections. 


\section{REFERENCES}

1- Andersen MG, Beck-Nielsen SS, Haubek D, Hintze H, Gjørup $H$, Poulsen S. Periapical and endodontic status of permanent teeth in patients with hypophosphatemic rickets. J Oral Rehabil. 2012;39(2):144-50.

2- Beltes C, Zachou E. Endodontic management in a patient with vitamin D-resistant Rickets. J Endod. 2012;38(2):255-8.

3- Breen GH. Prophylactic dental treatment for a patient with vitamin D-resistant rickets: report of case. ASDC J Dent Child. 1986;53(1):38-43.

4- Carpenter TO. New perspectives on the biology and treatment of X-linked hypophosphatemic rickets. Pediatr Clin North Am. 1997;44(2):443-66.

5- Chaussain-Miller C, Sinding C, Septier D, Wolikow M, Goldberg M, Garabedian M. Dentin structure in familial hypophosphatemic rickets: benefits of vitamin $D$ and phosphate treatment. Oral Dis. 2007;13(5):482-9.

6- Chaussain-Miller C, Sinding C, Wolikow M, Lasfargues JJ, Godeau G, Garabédian M. Dental abnormalities in patients with familial hypophosphatemic vitamin D-resistant rickets: prevention by early treatment with 1 -hydroxyvitamin D. J Pediatr. 2003;142(3):324-31.

7- Goodman JR, Gelbier MJ, Bennett JH, Winter GB. Dental problems associated with hypophosphataemic vitamin $D$ resistant rickets. Int J Paediatr Dent. 1998;8(1):19-28.

8- Hillmann G, Geurtsen W. Pathohistology of undecalcified primary teeth in vitamin D-resistant rickets: review and report of two cases. Oral Surg Oral Med Oral Pathol Oral Radiol Endod. $1996 ; 82(2): 218-24$.
9- Murayama T, Iwatsubo R, Akiyama S, Amano A, Morisaki I. Familial hypophosphatemic vitamin D-resistant rickets: dental findings and histologic study of teeth. Oral Surg Oral Med Oral Pathol Oral Radiol Endod. 2000;90(3):310-6.

10- Ozkan S, Ucok Z, Alagöl F. Dental manifestations of familial hypophosphatemic vitamin-D-resistant rickets: report of case. ASDC J Dent Child. 1984;51(6):448-50.

11- Rabbani A, Rahmani P, Ziaee V, Ghodoosi S. Dental problems in hypophosphatemic rickets, a cross sectional study. Iran J Pediatr. 2012;22(4):531-4.

12- Seow WK. Diagnosis and management of unusual dental abscesses in children. Aust Dent J. 2003;48(3):156-68.

13- Seow WK, Latham SC. The spectrum of dental manifestations in vitamin D-resistant rickets: implications for management. Pediatr Dent. 1986;8(3):245-50.

14- Shroff DV, McWhorter AG, Seale NS. Evaluation of aggressive pulp therapy in a population of vitamin D-resistant rickets patients: a follow-up of 4 cases. Pediatr Dent. 2002;24:347-9.

15- Yasufuku Y, Kohno N, Tsutsumi N, Ooshima T, Sobue S, Murakami $Y$, et al. Dental management of familial hypophosphatemic vitamin D-resistant rickets: report of case. ASDC J Dent Child. $1983 ; 50(4): 300-4$.

16- Zambrano M, Nikitakis NG, Sanchez-Quevedo MC, Sauk JJ, Sedano $H$, Rivera $H$. Oral and dental manifestations of vitamin D-dependent rickets type I: report of a pediatric case. Oral Surg Oral Med Oral Pathol Oral Radiol Endod. 2003;95:705-9. 